\title{
Neuropeptide Y Increases Both Ingestion of a Self-Selection Macronutrient Diet and Fos Expression in the Medial Amygdala of Rats*
}

\author{
Bruna Mombach Dietrich ${ }^{1}$, Marli Sita Scalcon ${ }^{1}$, Franklin Back ${ }^{2}$, Bárbara B. Philippi Martins ${ }^{2}$, \\ Elisa Cristiana Winkelmann-Duarte ${ }^{2}$, Alberto A. Rasia-Filho ${ }^{1,3 \#}$
}

${ }^{1}$ Graduation Course in Pathology, Federal University of Health Sciences of Porto Alegre, Porto Alegre, Brazil; ${ }^{2}$ Departments of Pharmacology and Morphological Sciences, Federal University of Santa Catarina, Florianopolis, Brazil; ${ }^{3}$ Department of Basic Sciences/Physiology, Federal University of Health Sciences of Porto Alegre, Porto Alegre, Brazil.

Email: rasiafilho@pq.cnpq.br, ${ }^{*}$ aarf@ufcspa.edu.br

Received June $14^{\text {th }}, 2013$; revised July $4^{\text {th }}, 2013$; accepted July $20^{\text {th }}, 2013$

Copyright (C) 2013 Bruna Mombach Dietrich et al. This is an open access article distributed under the Creative Commons Attribution License, which permits unrestricted use, distribution, and reproduction in any medium, provided the original work is properly cited.

\begin{abstract}
The rat posterodorsal medial amygdala (MePD) is responsive to the orexigenic neuropeptide Y (NPY) and is a putative candidate to participate in neural circuits that modulate feeding behavior. Here, we studied the effects of intracerebroventricular (icv) microinjection of NPY on the appetitive and food intake behaviors of rats under the paradigm of the self-selection macronutrient isolated diets [high-carbohydrate (high-CHO), high-protein and high-lipid food pellets]. At the same time, Fos expression was also evaluated in the MePD as a marker of local cellular activation. Adult male rats received icv microinjections of NPY ( $1 \mu \mathrm{g}$ and $10 \mu \mathrm{g} / 5 \mu \mathrm{L}, \mathrm{n}=10$ and 8 , respectively) whereas the control groups either received icv microinjection of artificial cerebrospinal fluid $(5 \mu \mathrm{L}, \mathrm{n}=8)$ or underwent sham procedure $(\mathrm{n}=8)$. The data were obtained after a fasting protocol. Feeding behavior was evaluated during a $2 \mathrm{~h}$ test period of free access to the selective diets. Rats in all groups preferred the high-CHO diet. Compared to controls, both doses of NPY increased the appetitive behaviors (searching for food and the frequency of attempts to eat any diet) and the percentage of animals eating high-CHO diet. However, only NPY at a dose of $1 \mu \mathrm{g}$ led to a significant increase in food intake and showed a strong positive correlation with Fos expression in the MePD ( $p<0.05$ in all cases). These new data reveal a biphasic effect of NPY on the appetite and food intake behaviors and suggest that the MePD participates in the NPY-induced feeding behavior in rats.
\end{abstract}

Keywords: Central Control of Appetite; Extended Amygdala; Feeding Behavior; Food Intake Behavior; Motivation

\section{Introduction}

Multiple neural systems control food intake, body weight and energy homeostasis in rats [1-4]. The central organization of feeding behavior-cue-induced feeding, associative learning, decision-making, reward and feed-back modulation of appetite, eating and satiety-involves various classical neurotransmitters, neuropeptides and hormones for motivation [3-6]. For example, glutamate, the main excitatory neurotransmitter, increases food intake when microinjected in the lateral nucleus of the hypothalamus [7,8], and the activation of glutamatergic NMDA receptors is needed for the orexigenic effects of

\footnotetext{
${ }^{*}$ Conflict of Interest: Authors declare no actual or potential conflict of interest.

${ }^{\#}$ Corresponding author.
}

neuropeptide Y (NPY) in this area [9]. Leptin and NPY show opposing actions on appetitive and food intake behavior [5].

The integration of feeding behavior with emotional processing and associative learning has been centered on some hypothalamic and extra-hypothalamic areas, including the "amygdala" $[10,11]$. The role of the different amygdaloid nuclei in feeding behavior is still under study [e.g., 6,10,12-14]. While basolateral, basomedial and lateral amygdaloid nuclei are involved in cue-driven intake, the central nucleus (CeA) is decisive for feeding cessation by an aversive conditioned stimulus in male rats [reviewed in 6,10]. Studies using large electrolytic lesion have shown that a wide area, named the "posterodorsal region" of the amygdala, could alter feeding behavior 
and induce hyperphagia and obesity in female rats $[15$, 16]. More specifically, damage of posterodorsal medial amygdala (MePD) and intra-amygdaloid bed nucleus of the stria terminalis (and also the globus pallidus) were mainly associated with an excess of weight gain in these female rats [17].

The MePD is one of the four major subnuclei of the medial amygdaloid nucleus (MeA) and is a complex part of the forebrain, subcortical extended amygdala in rats [18-22]. More recently, it was demonstrated that glutamate microinjection in the MePD induced only a subtle increase in the intake of a three-choice of macronutrient self-selection diet in male rats [14]. This finding is intriguing once other experimental approaches suggested that the MePD might be a modulatory area for feeding behavior in rats $[7,17,23]$. Moreover, the MePD affects relevant visceral reflex responses [24,25] and innervates, directly or via the stria terminalis (ST), the hypothalamic preoptic area, the ventromedial, the anteroventral periventricular, the arcuate, the paraventricular and the ventral premammillary nuclei [26-28]. All of them integrate various sensory inputs to control adaptive behaviors, including food intake and energy balance [1,2].

It would be interesting to examine whether other neurotransmitter or neuropeptide would affect the MePD function and the modulation of goal-oriented food intake [14]. NPY, one of the most widely expressed neuropeptides in the rat brain [29-31], is a putative candidate to elicit such feeding responses since it can induce both appetitive activities for food searching and has an intense orexigenic effect $[5,32-35]$. There is a moderate concentration of NPY-immunoreactive perikarya, but a high density of fibers, in the dorsal half of the MeA [36], especially in the MePD of rats [37]. Although the mRNA encoding NPY Y5 receptor is weakly observed in the $\mathrm{MeA}$ of rats [33], a prominent population of neurons expressing NPY Y1 receptor [38] and the NPY Y2 receptor [39] are found in this nucleus. These data are relevant given that NPY Y1 and Y5 receptors basically mediate the effects of NPY on central feeding behavior [40].

Here, we tested the effects of intracerebroventricular (icv) microinjections of NPY on the appetite and food intake behaviors of rats under the paradigm of major macronutrient-specific dietary selection. Also, Fos immunolabeling was evaluated in the MePD as a marker of local cells activation [according to 22,26] following the same rationale of previous studies on the central effects of NPY or other orexigenic neuropeptides $[4,6,29,30]$. We tested the correlation between the occurrence of feeding behavior and the number of Fos-immunoreactive cells in the MePD.

\section{Materials and Methods}

The present methodological approach was adapted from
Rosa et al. [14].

\subsection{Animals}

All animals were adult male Wistar rats $(\mathrm{N}=34,3$ - 4 months old; body weight, mean $\pm \mathrm{SD}=234.1 \pm 9.8$ grams) initially housed in groups with standard lab chow (Bio Base/Bio-Tec, Brazil) and water ad libitum, at room temperature of $22^{\circ} \mathrm{C}$ and a $12 \mathrm{~h} \mathrm{light/dark} \mathrm{cycle} \mathrm{(lights} \mathrm{on}$ at 6 a.m.). All efforts were made to minimize the number of animals studied and their suffering. Rats were manipulated according to international laws for the ethical care and use of laboratory animals (European Communities Council Directive of November 1986, 86/609/EEC). The present project was approved by the local Ethics Committee (Federal University of Health Sciences of Porto Alegre, Brazil; protocol no. 563/09).

\subsection{Experimental Procedure}

The procedural design included adapting periods, and control and test recordings along 16 experimental days (EDs; Figure 1). In the first ED, each rat was placed in an individual metabolic cage $\left(21 \times 24 \times 21 \mathrm{~cm}^{3}\right.$ of length, size and height, respectively; in accordance with the "Guide for the Care and Use of Laboratory Animals," National Academy of Science, USA, 1996). The rats had a 4 days initial period of adaptation to its new environment. During this period, there was free access to food pellets of a full nutrient diet based on the AIN-93M (composition and kilocalories are shown in Table 1; consumption values in Table 2, ED 4). Water was available during all the EDs. The urine aspect and volume did not indicate signs of dehydration at any moment (data not shown). In every ED, food intake was evaluated by the difference of weight of the available food between the initial and the end of the monitoring period. Spillage was collected on paper towels and subtracted from food intake to correct the obtained values. Rat body weight was evaluated each day along the experiment. No behavioral test for depression or plasma stress hormones measurements were performed to directly determine possible side-effects of isolation to avoid undue stress to the rats. Nevertheless, during this initial period of isolation, and more notably thereafter, rats displayed a constant and homogeneous increase in body weight and no signs of illness or abnormal behaviors, as reported elsewhere [14].

On the EDs 5 to 8 , rats received a three-choice selfselection macronutrient isolated diets [pellets of highcarbohydrate (high-CHO), high-protein and high-lipid diets; compositions and kilocalories as described in Table 1]. Diets were offered in separate dishes attached to the metabolic cage. The location of each dish inside 


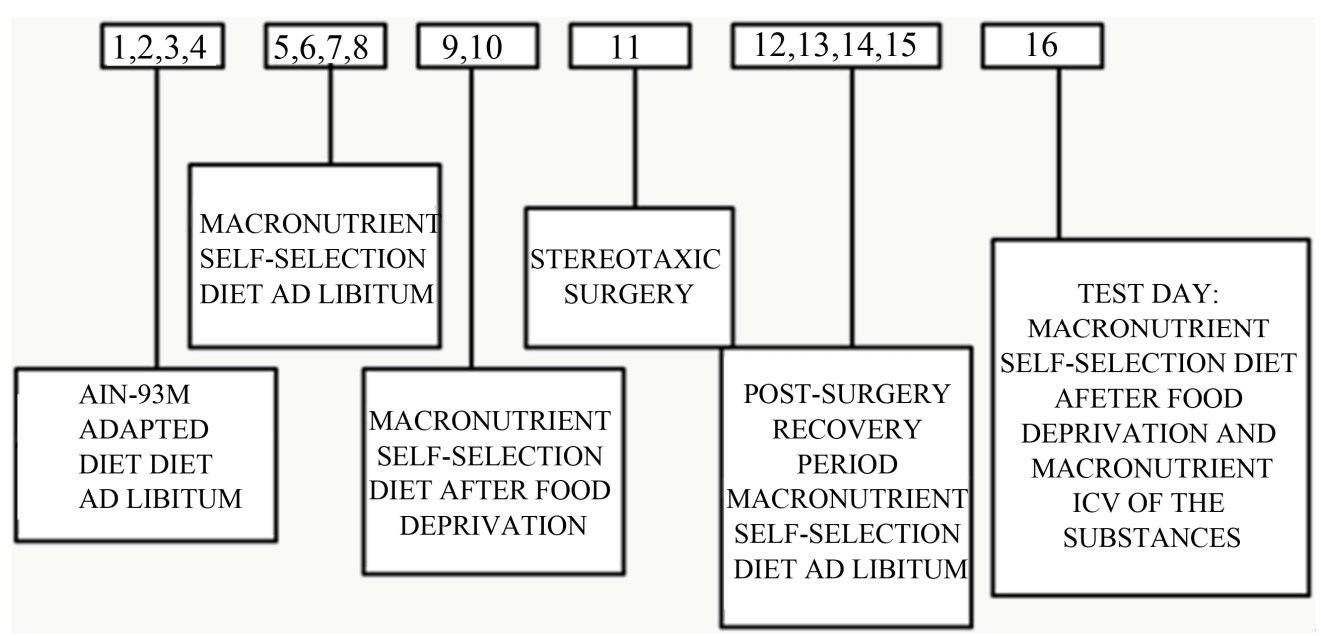

Figure 1. Experimental design (in days) and behavioral test schedule.

Table 1. Diet compositions (adapted from Rosa et al., 2011).

\begin{tabular}{|c|c|c|c|c|}
\hline \multirow[b]{2}{*}{ Nutrients ${ }^{*}$} & \multicolumn{4}{|c|}{ Diets } \\
\hline & AIN-93M (Adapted) & High-CHO & High-PTN & High-LIP \\
\hline Carboxymethylcellulose & 1.0 & 2.0 & 2.0 & 2.0 \\
\hline Casein & 14.0 & - & 87.96 & - \\
\hline Celullose & 5.0 & 5.0 & 5.0 & 5.0 \\
\hline Citric acid & 0.01 & 0.01 & 0.01 & 0.01 \\
\hline Cornstarch & 60.96 & 78.14 & - & - \\
\hline Food dye & 0.1 & 0.1 & 0.1 & 0.1 \\
\hline Hidrogenated vegetable fat & 2.0 & - & - & 79.39 \\
\hline L-cystine & 0.18 & - & 0.18 & - \\
\hline Mineral mix ${ }^{* *}$ & 3.5 & 3.5 & 3.5 & 7.0 \\
\hline Soybean oil & 2.0 & - & - & 4.0 \\
\hline Sugar & 10.0 & 10.0 & - & - \\
\hline Vitamin $\operatorname{mix}^{* *}$ & 1.25 & 1.25 & 1.25 & 2.5 \\
\hline
\end{tabular}

${ }^{*}$ Nutrients expressed as percent by weight diet. ${ }^{* *}$ The vitamin and mineral mixes contain $97.47 \%$ and $21 \%$ cellulose respectively, according to AIN $-93 \mathrm{M}$.

Table 2. Diet intake along different experimental days (EDs) and procedures.

\begin{tabular}{|c|c|c|c|c|c|}
\hline \multirow[t]{2}{*}{ Groups } & \multirow[t]{2}{*}{ EDs } & \multicolumn{4}{|c|}{ Diet intake (g) } \\
\hline & & AIN-93M Adapted & High-CHO & High-PTN & High-LIP \\
\hline Sham & $\begin{array}{c}4 \\
8 \\
10 \\
16\end{array}$ & $16.6(15.9 / 17.1)$ & $\begin{array}{c}12.2(11.3 / 13.4) \\
0.2(0 / 1.1) \\
0.2(0 / 1.1)\end{array}$ & $\begin{array}{c}3.7(3.2 / 4.2) \\
0(0 / 0) \\
0(0 / 0)\end{array}$ & $\begin{array}{c}0.6(0.3 / 0.7) \\
0(0 / 0) \\
0(0 / 0)\end{array}$ \\
\hline aCSF & $\begin{array}{c}4 \\
8 \\
10 \\
16\end{array}$ & $17.6(16.5 / 18.1)$ & $\begin{array}{c}13.0(11.6 / 14.4) \\
0.2(0 / 1.1) \\
0.2(0 / 1.1)\end{array}$ & $\begin{array}{c}3.5(2.2 / 4.5) \\
0(0 / 0) \\
0(0 / 0)\end{array}$ & $\begin{array}{c}1.0(0.6 / 1.1) \\
0(0 / 0) \\
0(0 / 0)\end{array}$ \\
\hline $\begin{array}{l}\text { NPY } \\
1 \text { ug }\end{array}$ & \begin{tabular}{c|}
4 \\
8 \\
10 \\
16
\end{tabular} & $11.2(8.2 / 16.7)$ & $\begin{array}{c}13.6(13.1 / 15.3) \\
0(0 / 0.5) \\
1.7(1.1 / 1.9)^{* *}\end{array}$ & $\begin{array}{c}4.6(3.6 / 4.8) \\
0(0 / 0.1) \\
0(0 / 0)\end{array}$ & $\begin{array}{c}1.0(0.9 / 1.1) \\
0(0 / 0.3) \\
0(0 / 0.1)\end{array}$ \\
\hline $\begin{array}{l}\text { NPY } \\
\text { 10ug }\end{array}$ & $\begin{array}{c}4 \\
8 \\
10 \\
16\end{array}$ & $11.5(8.4 / 16.9)$ & $\begin{array}{c}13.6(10.9 / 13.6) \\
0(0 / 0.6) \\
1.1(1.0 / 2.0)\end{array}$ & $\begin{array}{c}3.7(3.1 / 4.1) \\
0(0 / 0) \\
0(0 / 0.1)\end{array}$ & $\begin{array}{c}0.5(0.1 / 1.0) \\
0(0 / 0) \\
0(0 / 0)\end{array}$ \\
\hline
\end{tabular}


the cage was changed daily to avoid biases resulting from a conditioned place preference. The "palatability" of the high-CHO diet was not intentionally enhanced by adding sweet monosaccharides and disaccharides. Although it is possible that few corn starch had been broken in less complex sugars, heating temperature that induce the formation of a final high amount of dextrin was avoided during the diet preparation [c.f., 14]. Values of daily intake of these selective diets are shown in Table 2 (on ED 8).

On the ED 10, rats underwent food deprivation for $4 \mathrm{~h}$ (from 8 a.m. to 12 a.m.) and, thereafter, allowed to eat the macronutrient isolated diets during $2 \mathrm{hr}$. During this period, the appetitive and the food intake behaviors were observed. The parameters to evaluate the appetitive behaviors included, the number of attempts to reach each macronutrient isolated diet and the frequency of attempts to eat a pellet of any diet. The amount of food intake of each self-selection diet in grams was indicative of food intake behavior. The data obtained from ED 10 was the baseline (Table 2, on ED 10) and was compared with the data obtained on the upcoming test day. The importance of this comparison was addressed previously [14,22].

On the ED 11 (beginning at 8 a.m.), rats were anesthetized with ketamine and xylazine $(80$ and $10 \mathrm{mg} / \mathrm{kg}$, i.m., respectively) and stereotaxically implanted with a stainless steel guide cannula ( $0.6 \mathrm{~mm}$ of outer diameter, OD) in the right lateral ventricle of the brain. The stereotaxic coordinates were: $1.0 \mathrm{~mm}$ posterior to the bregma, 1.5 $\mathrm{mm}$ lateral to the midsagital suture and $3.5 \mathrm{~mm}$ below the dura-mater [adapted from 41]. The upper incisor bar was positioned horizontally to the interaural line.

The animals were allowed to recover from surgery for 2 days (EDs 12 and 13) and had free access to the isolated macronutrient diet. On the EDs 14 and 15, rats were gently manipulated to simulate the icv microinjection procedure (described below) and were again allowed to eat the isolated macronutrient diets until the next day.

On the ED 16, rats were deprived of food for $4 \mathrm{~h}$ and, thereafter, the feeding tests were initiated at 12 am for all the experimental groups to avoid circadian effects on the results. Rats were randomly assigned to receive artificial cerebrospinal fluid (aCSF, $5 \mu \mathrm{L}, \mathrm{n}=8)$ or NPY $(1 \mu \mathrm{g}$ or $10 \mu \mathrm{g} / 5 \mu \mathrm{L}$ diluted in aCSF, $\mathrm{n}=10$ and 8 , respectively). The aCSF composition was: $\mathrm{NaCl} 126 \mathrm{mM}, \mathrm{KCl} 2.5 \mathrm{mM}$, $\mathrm{NaH}_{2} \mathrm{PO}_{4} 1.25 \mathrm{mM}, \mathrm{MgCl}_{2} 2 \mathrm{mM}, \mathrm{CaCl}_{2} 2 \mathrm{mM}, \mathrm{Na}-$ $\mathrm{HCO}_{3} 26 \mathrm{mM}$, and glucose $10 \mathrm{mM}$ [42]. NPY was purchased from Sigma Chemicals Co. (USA). Both doses of NPY were previously reported as able to promote marked behavioral effects, some lasting from 1 to $24 \mathrm{~h}$ $[5,43]$. The microinjection needle $(0.3 \mathrm{~mm}$ OD) was introduced by the stereotaxic guide cannula for the icv microinjections and the displacement of liquid and an air bubble inside the catheter connecting to a $10 \mu \mathrm{L}$ Hamilton microsyringe (USA) was used to monitor the procedure. This lasted for 1 minute and the needle remained inside the cannula for an additional minute to avoid reflux $[14,25]$. No obvious alterations in behavior were observed after microinjections. An additional control group for the experimental procedures was assigned for sham microinjection $(n=8)$, i.e., these rats were anesthetized and had an icv cannula, the needle was inserted and rats were manipulated as the other experimental groups, but did not receive any treatment.

Immediately afterwards, rats returned to their metabolic cage and had access to the three-choice macronutrient self-selection diet. The intake of each diet was evaluated at the end of $2 \mathrm{~h}$ following microinjection (shown in Table 2, on ED 16). It was observed the number of the appetitive behaviors and the ingested amount of each isolated macronutrient diet taken. The percentage of animals that had taken the selective diets in each experimental group was also calculated.

At the end of the experiment, rats were deeply anesthetized as above-mentioned and icv microinjected with methylene blue to identify the location of the microinjection site. Rats were transcardially perfused with phosphate buffer solution (PBS, $0.1 \mathrm{M}, \mathrm{pH}$ 7.4) followed by $4 \%$ paraformaldehyde diluted in PBS. Brains were removed from the skull, remained in the same fixative solution for $12 \mathrm{hr}$, transferred to a $30 \%$ sucrose solution at $4^{\circ} \mathrm{C}$ for at least 1 week and, thereafter, were sectioned using a vibratome (Leica, Germany; $50 \mu \mathrm{m}$-thick coronal sections) to identify the path of the icv cannula. Animal with signals of large mechanical lesions or brain hemorrhage was excluded of the studied groups. The same brains were used to study of Fos expression in the MePD. The MePD was recognized by its ventral location to the ST and lateral position to the optic tract in the rat ventral forebrain, 2.76 to $3.48 \mathrm{~mm}$ posterior to the bregma [41]. Both hemispheres were studied. Brain sections were initially coded and kept immersed in an anti-freeze solution (PBS, distilled water, sucrose, and propylene glycol) and stored at $70^{\circ} \mathrm{C}$ in biofreezer until further processing.

The Fos immunohistochemistry was carried out using the avidin-biotin peroxidase method as previously described [44]. Free-floating brain sections were washed in PBS and incubated in a solution containing PBS, Triton X-100 (Sigma Chemicals Co., USA), goat serum and anti-Fos antiserum raised in rabbit (Ab-5; Calbiochem, USA) diluted 1:20.000 for $48 \mathrm{~h}$ at $4{ }^{\circ} \mathrm{C}$ and continuous shaking. Sections were then incubated during $90 \mathrm{~min}$ at room temperature in a solution of biotinylated goat anti-rabbit $\operatorname{IgG}(1: 200$; Vector, USA) and then placed in 
the a mixed avidin-biotin horseradish peroxidase complex solution (1:200; ABC Elite Kit; Vector, USA) for the same time. The peroxidase complex was visualized after a 10 min exposure to a chromogen solution containing $0.02 \%$ 3,30-diaminobenzidine tetrahydrochloride (Sigma Chemicals Co., USA) with $0.3 \%$ nickel ammonium sulfate in $0.05 \mathrm{M}$ Tris-buffer ( $\mathrm{pH}$ 7.6), followed by incubation for $5 \mathrm{~min}$ in chromogen solution with glucose oxidase (Glucose Oxidase Type VII from Aspergillus Niger, $0.01 \%$, Sigma Chemicals Co., USA) and $10 \%$ pD-glucose (Sigma Chemicals Co., USA). Sections were rinsed in PBS, dehydrated in ethanol, washed with xylene and covered with DPX (distyrene/plasticizer/xylene) synthetic balsam and coverslips. All experimental groups were processed altogether to avoid possible unspecific variations in the procedures and their results. To control the enzymatic activity, some random sections were performed omitting the primary antiserum, which provided no detectable Fos-immunostaining and a "negative" background aspect (data not shown).

The images of the cellular Fos expression were similar to those published elsewhere $[22,30,44]$ and staining pattern was empirically considered adequate for further comparisons among groups. Quantification of the number of Fos immunoreactive (Fos-ir) cells in the MePD was made according to previous reports $[22,45]$. The criteria to identify and to calculate Fos-ir cells in the MePD included the following: the cells must a) be within the including borders of an overlaid rectangle named here as the "area of interest" $\left[0.36 \mathrm{~mm}^{2}\right.$, Figure 2(A)]; b) have a staining color notably contrasting with the background; and, c) have identifiable nuclear cell borders [Figure 2(B)]. All microscopic images lightning and contrast conditions were maintained identical during the experimental data acquisition. Five sections per rat were studied ( $\mathrm{n}=5$ rats for the sham and NPY $10 \mu \mathrm{g}$ groups, $\mathrm{n}$ $=6$ rats for the aCSF and NPY $1 \mu \mathrm{g}$ groups). Direct calculation of Fos-ir cells in the MePD were performed by two independent observers using an optic microscope (400 x; Olympus BX-61, Japan) coupled to a high-performance CCD DP72 camera (Olympus, Japan) and an image processing software (Image Pro Plus 7.0, Media Cybernetics, USA). Fos-ir cells were also observed in the hypothalamic periventricular nucleus (PVN) and the dorsomedial nucleus (DMH), previously described as critically involved with food intake behavior $[1,30,40]$ and food-anticipatory activity [46,47], respectively, as well as with the central effects of NPY $[29,30,40]$. It was not the scope of the present work to depict the presence of Fos-ir in the different hypothalamic nuclei, which was already done indeed $[29,30]$. Nevertheless, the presence of Fos-ir cells in these above-mentioned hypothalamic nuclei served as additional "internal" control data for the Fos expression in our studied animals.

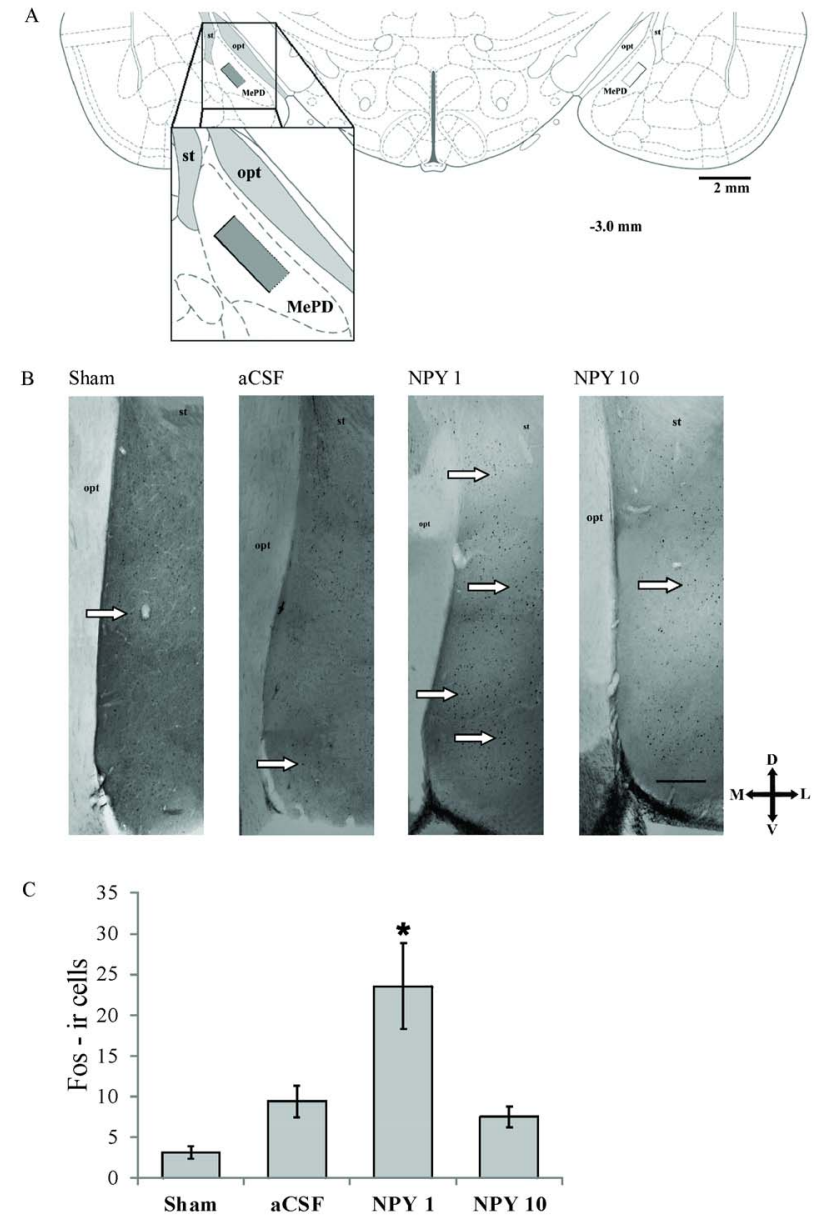

Figure 2. A. Schematic diagram of a coronal brain section showing the right and left posterodorsal medial amygdala (MePD, approximately $3.0 \mathrm{~mm}$ posterior to the bregma, as an example of the sampled sections studied here). The overlaid rectangle (the "area of interest" of $0.36 \mathrm{~mm}^{2}$ ) represents the site where Fos-immunoreactive cells were calculated. Both hemispheres were studied. opt = optic tract, st $=$ stria terminalis. Adapted from [41]. B. Reconstructed photomicrographs of Fos immunolabeling in the MePD of NPY icv microinjection group ( $1 \mu \mathrm{g}$ or $10 \mu \mathrm{g} / 5 \mu \mathrm{L}$ diluted in aCSF, $n=10$ and 8 , respectively) and control groups [sham $(n=8)$ or after icv microinjection of artificial cerebrospinal fluid (aCSF, $5 \mu \mathrm{L}, \mathbf{n}=8$ )]. Background and contrast were adjusted (Adobe Photoshop 7.0, USA), and the same criteria to calculate the cells were adopted for all experimental groups (see text for further details). Arrows point to some Fos-immunoreactive cell. Scale bar $=20 \mu \mathrm{m}$. Spatial coordinates are: $\mathbf{D}=$ dorsal, $\mathrm{L}=$ lateral, $\mathbf{M}=$ medial, $\mathrm{V}=$ ventral. C. Values are mean \pm standard error of the mean of Fos-ir cells in the MePD of the studied experimental groups. ${ }^{*}$ p < 0.05 compared to all other groups.

\subsection{Statistical Analysis}

Analysis of variance (ANOVA) test for repeated measures followed by the Tukey test was used to evaluate the weight gain of the rats during the EDs 1,10 and 16 . 
After logarithmic transformation, the searching for food and frequency of attempts to eat a pellet of any diet and the amount of the high-CHO diet intake on EDs 10 and 16 were compared among groups using ANOVA test for repeated measures followed by the Newman-Keuls test for multiple comparisons. Fisher exact test was used to compare the percentage of rats of each group that have taken high CHO diet intake on ED 16. The low intake of the high-protein and the high-lipid selective diets prevented further statistical comparisons among groups.

After square root transformation, Fos expression data were compared among groups by the one-way ANOVA test followed by the Tukey test. The nonparametric Spearman rank test was used to correlate the frequency of the appetitive behaviors and the amount of food intake with the number of Fos-ir cells counted in the MePD. In all cases, results were considered significant when $P \leq$ 0.05 .

\section{Results}

\subsection{Body Weight}

Animals in all groups showed increased values of body weight along the EDs 1, 10 and 16 [mean \pm standard deviation (SD), $234.1 \pm 9.8 ; 241.9 \pm 9.8$; and, $261.1 \pm 15.6$ grams, respectively], which were statistically significant [ANOVA test, $\mathrm{F}(2,98)=99.61 ; P<0.01]$ and different from each other (Tukey test, $P<0.01$ in all cases).

\subsection{Appetitive Behaviors and Selective Diet Intake}

Data are shown in Tables 2 and 3. Animals in all groups showed a similar intake of AIN-93M diet during the first EDs (see mean values on ED 4). When rats had free access to the self-selection macronutrient diet, all groups showed a clear preference for the high-CHO diet when compared to the other diets (see mean values on ED 8). Following $4 \mathrm{~h}$ of food deprivation and the subsequent $2 \mathrm{~h}$ of free access to the 3-choice self-selection macronutrient diet, rats of all groups also had taken more high-CHO diet (see mean values on ED 10) and small amount of high-protein and high-lipid diets (Table 2).

There was a significant difference among experimental groups in the appetite behaviors of searching for food dishes [ANOVA test, $F(3,29)=11.66 ; P<0.01]$ and the frequency of eating the pellets of any selective diet on the ED 16 [ANOVA test, F $(3,29)=10.32 ; P<0.01$ ]. There was no difference between sham and aCSF microinjected groups (Newman-Keuls test, $P>0.05$ ), whereas both doses of NPY increased these appetitive behaviors when compared to the control groups (Newman-Keuls test, $P<0.05$; Table 3).

There was also a significant difference in the intake of the high-CHO diet between groups [ANOVA test, $\mathrm{F}$ $(7,55)=3.54 ; P<0.01]$. The Newman-Keuls post hoc test showed that all groups had a similar intake of this diet on the control ED $10(P>0.05)$, whereas differences among groups were found on the test day, ED 16. Data from the sham and the aCSF microinjected groups were not statistically different $(P>0.05)$. On the other hand, the microinjection of NPY $1 \mu \mathrm{g}$ led to an increased intake of the high-CHO diet, which became different from the values obtained in this same group on the ED $10(P<$ $0.01)$ and when compared to both sham and aCSF data on the ED $16(P<0.05)$. This same effect was not observed in the group microinjected with NPY $10 \mu \mathrm{g}(P>$ 0.05; Table 2).

There was no significant difference in the percentage of rats that had taken the high-CHO diet on the EDs 10 and 16 for sham and aCSF microinjected groups (percentages ranging from $50 \%$ to $75 \%$ in both groups; Fisher test, $P>0.6$ ). On the other hand, all tested rats had taken the high-CHO diet after icv microinjection of both doses of NPY on EDs 10 and 16 (Fisher test, $P<0.03$ ).

\subsection{Fos Expression}

Results are shown in Figure 2(C). There was a significant difference in the number of Fos-ir cells in the MePD among experimental groups [ANOVA test, $\mathrm{F}(3,17)=$ 11.18; $P<0.01]$. Additionally, the animals receiving NPY $1 \mu \mathrm{g}$ had higher number of Fos-ir cells when compared to the sham, the aCSF and the NPY $10 \mu \mathrm{g}$ experimental groups (Tukey test, $P<0.05$ in all cases). No statistical difference was found among these three latter groups (Tukey test, $P>0.05$ ).

Table 3. Appetitive behaviors.

\begin{tabular}{ccccccc}
\hline Groups & \multicolumn{3}{c}{ Frequency of Searching for Food } & \multicolumn{2}{c}{ Frequency of Attempts to Eat } \\
\hline & High-CHO & High-PTN & High-LIP & High-CHO & High-PTN & High-LIP \\
\hline Sham & $1.6 \pm 0.7$ & $1.3 \pm 0.5$ & $0.8 \pm 0.7$ & $1.4 \pm 1.3$ & $0.6 \pm 0.7$ & $0 \pm 0$ \\
aCSF & $1.6 \pm 1.3$ & $1.3 \pm 0.9$ & $1.0 \pm 1.0$ & $0.9 \pm 0.9$ & $0.4 \pm 0.7$ & $0.1 \pm 0.3$ \\
NPY 1 ug & $8.9 \pm 6.2^{*}$ & $7.5 \pm 7.0^{*}$ & $4.7 \pm 2.4^{*}$ & $6.9 \pm 3.8^{*}$ & $0.9 \pm 1.9^{*}$ & $0.4 \pm 0.7^{*}$ \\
NPY 10 ug & $5.8 \pm 3.8^{*}$ & $4.1 \pm 2.5^{*}$ & $3.0 \pm 2.7^{*}$ & $5.5 \pm 4.4^{*}$ & $0 \pm 0$ & $0.1 \pm 0.3$ \\
\hline
\end{tabular}


The correlation between the number of MePD Fos-ir cells, the appetitive behaviors display and the amount of high-CHO diet intake was tested specifically in the group receiving icv microinjection of NPY $1 \mu \mathrm{g}$. There was no correlation between the number of Fos-ir cells in the MePD and the frequency of searching for the food dishes [Spearman test, $P=0.24$; Figure 3(A)] or the frequency of eating pellets of any selective diet [Spearman test, $P=$
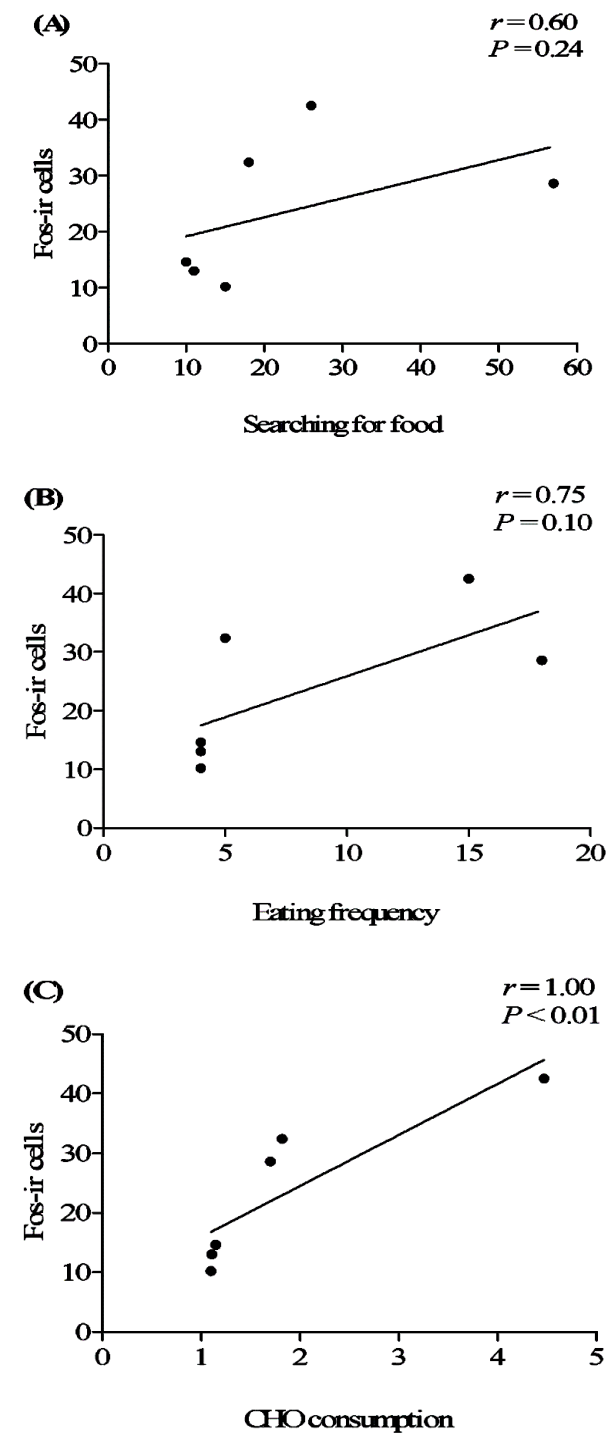

Figure 3. Relationship (Spearman's correlation) between the number of Fos-immunoreactive cells in the rat posterodorsal medial amygdala and the number of attempts of the appetitive behaviors of (A) searching for food and (B) frequency of attempts to eat the available self-selection macronutrient diets or (C) the consummatory behavior of taking the high-CHO selective diet (intake in grams) during a test period of 2 hours after the central microinjection of NPY $(1 \mu \mathrm{g} / 5 \mu \mathrm{L}$, icv, $\mathbf{n}=6)$. A highly significant correlation was only found in (C), as evidenced by the respective $r$ and $P$ values.
0.10; Figure 3(B)]. However, there was a highly significant and positive correlation between the amount of high-CHO diet consumption and the number of MePD Fos-ir cells [Spearman test, $P<0.01$; Figure 3(C)].

Finally, as control data, Fos expression in the PVN resembled that found in the MePD, with higher amount of Fos-ir cells in the NPY $1 \mu \mathrm{g}$ microinjected group when compared with the others (data not shown). In the DMH, Fos-ir in the MePD appeared to be similar for control and NPY microinjected groups (data not shown).

\section{Discussion}

In this study, we showed that the rats were well adapted to the experimental protocol, exhibited a continuous body weight gain along the EDs and had a preference for the high-CHO selective diet. Sham and aCSF microinjected groups had similar results and served as control. NPY increased the food intake behavior with a biphasic effect under the present behavioral paradigm. That is, microinjection of NPY $1 \mu \mathrm{g}$ was able to stimulate the searching for food, the frequency of attempts to eat any selective diet and induced a higher $\mathrm{CHO}$ intake. The NPY-mediated orexigenic effect (on food intake behavior rather than on appetitive behaviors) has a strong correlation with the number of Fos-ir cells in the MePD. On the other hand, NPY $10 \mu \mathrm{g}$ stimulated appetitive behaviors, but did not consistently affect the food intake behavior or the Fos expression in the MePD when compared to the aCSF microinjected group.

Previous data showed that NPY can direct the attention towards food in a dose-dependent manner [5] and/or can increase the motivation for food intake by modulating appetite and hunger [32]. The enhanced high-CHO diet intake described here agrees with other reported effects of centrally administered NPY in rats $[34,43,48,49]$. However, under the present behavioral test, lower and higher doses of NPY did not promote quite related results on food intake behavior and MePD Fos-ir cells number. Recent findings made clear that, indeed, the MePD responded differently to increase amount of neurotransmiters and neuromodulators locally microinjected, likely coding for distinct synaptic strength and for the specific "fine-tuning" of behavioral displays [further discussed in 14,22,24,25,50; see conceptual comments in 4,51].

Our study of Fos expression was based on previous similar procedures that revealed the functional roles of the MePD on social/motivated behaviors $[22,45,52,53]$ and the activation of brain areas following NPY action $[29,30]$. Here, control observations of Fos-ir in the PVN and $\mathrm{DMH}$ occurred as expected for their function. In addition, Fos expression was similar to that described previously by others $[29,30,40,46,47]$. It is worth to mention that the enhanced Fos-ir in the MePD observed 
following NPY microinjection could be a direct effect of NPY signaling on this subnucleus, an indirect consequence of the activation of interconnected neural networks for feeding behavior. Alternatively, it could be secondary to the different amount of food intake. There are evidences in favor of all these possibilities. First, NPY innervation and receptors are found in the MePD [36-38] and icv microinjected NPY could reach the MePD caudal part of the wall of the lateral ventricle $[18,41]$. Second, the MePD has direct and indirect connections with hypothalamic areas that modulate feeding behavior $[17,28]$, and are sensitive to centrally administered NPY. These areas also show marked Fos-ir in rats allowed to feed after NPY microinjection [30], such as the PVN and the DMH. However, lesions of the entire MeA or ST did not reduce the density or the distribution of NPY immunoreactive terminal fields in the basal forebrain or in the hypothalamus, suggesting that immunoreactive neurons in the MeA did not contribute significantly to these innervations [36]. On the other hand, widespread neurons that synthesized or responded to NPY can really establish little functional dependence among them and represented redundant neuronal mechanisms for feeding behavior [additional comments in 23]. Third, there was a positive correlation between Fos-ir in the $\mathrm{MePD}$ and the amount of food intake following icv microinjection of NPY $1 \mu \mathrm{g}$. Clearly, these are not mutually exclusive possibilities and, in common, they indicate that the rat MePD is activated during feeding behavior. This is a new an interesting venue revealed by the present data.

Furthermore, it would be also possible that other physiological factors could account for the Fos-ir in the MePD following NPY icv microinjection. The MePD can elicit homeostatic or adaptive general adjustments in the context of emotional/social stimuli processing [21,22, 26,54] and NPY Y1 receptors in the whole amygdala are important to generate anxiolytic effects seen in rats tested in the elevated plus maze test [55]. The NPY Y1 receptor was notably found in the MeA subnuclei [38] and the present icv microinjection of NPY would have stimulated both food intake and anticonflict/anxiolytic-like effects in rats. However, ibotenic acid neurotoxic damage of the MePD was not able to modify any parameter of anxietylike behavior in lesioned rats studied in the same plus maze test [22]. The CeA is another component of the extended amygdala along with the MeA subnuclei [18], and local microinjections of NPY $(0.1,0.3$ and $1.0 \mu \mathrm{g}$ in $1 \mu \mathrm{l}$ of saline) after overnight fasting increased high-CHO food intake and reduced high fat diet at $24 \mathrm{~h}$ post-injection in rats [34]. NPY or a selective NPY Y1 receptor agonist microinjected directly in the CeA reduced anxiety without increasing meal consumption [56]. Altogether, these findings indicate a likely dissociation between anxiolytic-like actions and food intake effects in the $\mathrm{MePD}$ and CeA of rats. Novel, conflictive or stressful experimental condition appears not to be responsible for marked Fos-ir cells in the MePD, as evidenced by the lower Fos expression in the control groups (sham and icv aCSF microinjection) subjected to the same paradigm. Also, there are no direct data that prove the involvement of the MePD in other aspects of feeding behavior, such as learning of appetitive motivated tasks [reviewed in 57]. Other studies are needed to test if NPY action in the MePD relates to food-anticipatory responses and preparation for scheduled feeding [58] or to prepare the animal to consume a calorically large meal [59]. Currently, evident experimental differences (e.g., Long-Evans adult females vs Wistar adult males) hamper the direct comparison of our data with large electrolytic lesions of the "posterodorsal region" of the amygdala, which induced hyperphagia and obesity in lesioned female rats [14-16], even more because the MePD is sexually dimorphic and affected by ovarian steroid fluctuations along the estrous cycle [19,21; and references therein].

Finally, some important issues should be mentioned to direct future efforts. Here we show the correlation between NPY-induced selective high-CHO diet intake and Fos expression in the MePD. These data suggest the participation of this subnucleus in goal-oriented feeding behavior and highlight the MePD as a subcortical component of different social behavior neural networks [22, based on 26]. The dual effects of NPY can also add to the scholarly debate about the actual distinction between appetitive vs consummatory behaviors [see critical comments in 60]. In addition, from the insightful proposition of Zeltser et al. [4] on brain regions that participate in energy homeostasis, the MePD shows notable dendritic spines and synaptic plasticity [21], modulates reproduction [22] and can be part of dynamic neuronal circuits that regulate the balance between energy intake and expenditure. Then, future research can involve the direct microinjection of NPY in the MePD to test feeding behavior and compare the present results with those to be obtained with this additional experimental approach. Other amygdaloid nuclei should be tested as well. It is also highly deserved to reveal whether NPY acting in the MePD would play a role in pathological conditions that involve feeding behavior disturbances. These are opened possibilities now awaiting further advancements.

\section{Acknowledgements}

Authors are thankful to M.Sc. Carolina Böetge Rosa, M.Sc. Daniela Haas and Ms. Renata V. de Souza (Brazil) for their contribution to the experimental protocol. Also, to Dr. Maria Elisa Calcagnotto (Brazil) for her suggestions. Grants from the Brazilian Founding Agency CNPq. 
$\mathrm{AARF}$ is a CNPq researcher.

\section{REFERENCES}

[1] H. R. Berthoud, "Multiple Neural Systems Controlling Food Intake and Body Weight," Neuroscience \& Biobehavioral Reviews, Vol. 26, No. 4, 2002, pp. 393-428. doi:10.1016/S0149-7634(02)00014-3

[2] J. W. Hill, J. K. Elmquist and C. F. Elias, "Hypothalamic Pathways Linking Energy Balance and Reproduction," American Journal of Physiology: Endocrinology and Metabolism, Vol. 294, No. 5, 2008, pp. E827-E832. doi:10.1152/ajpendo.00670.2007

[3] K. W. Williams and J. K. Elmquist, "From Neuroanatomy to Behavior: Central Integration of Peripheral Signals Regulating Feeding Behavior," Nature Neuroscience, Vol. 15, No. 10, 2012, pp. 1350-1355. doi:10.1038/nn.3217

[4] L. M. Zeltser, R. J. Seeley and M. H. Tschöp, "Synaptic Plasticity in Neuronal Circuits Regulating Energy Balance," Nature Neuroscience, Vol. 15, No. 10, 2012, pp. 1336-1342. doi:10.1038/nn.3219

[5] A. A. Ammar, F. Sederholm, T. R. Saito, A. J. W. Scheurink, A. E. Johnson and P. Soderstern, "NPY-Leptin: Opposing Effects on Appetitive and Consummatory Ingestive Behavior and Sexual Behavior," American Journal of Physiology, Vol. 278, No. 6, 2000, pp. 1627-1633.

[6] G. D. Petrovich, "Forebrain Networks and the Control of Feeding by Environmental Learned Cues," Physiology \& Behavior, 2013, in Press.

doi:10.1016/j.physbeh.2013.03.024

[7] B. G. Stanley, V. L. Willett, H. W. Donias, L. H. Ha and L. C. Spears, "The Lateral Hypothalamus: A Primary Site Mediating Excitatory Amino Acid-Elicited Eating," Brain Research, Vol. 630, No. 1-2, 1993, pp. 41-49. doi:10.1016/0006-8993(93)90640-9

[8] M. A. Duva, E. M. Tomkins, L. M. Moranda, R. Kaplan, A. Sukhaseum, A. Jimenez and B. G. Stanley, "Reverse Microdialysis of N-Methyl-D-Aspartic Acid into the Lateral Hypothalamus of Rats: Effects on Feeding and Other Behaviors," Brain Research, Vol. 921, No. 1-2, 2001, pp. 122-132. doi:10.1016/S0006-8993(01)03108-0

[9] S. W. Lee and B. G. Stanley, "NMDA Receptors Mediate Feeding Elicited by Neuropeptide $\mathrm{Y}$ in the Lateral and Perifornical Hypothalamus," Brain Research, Vol. 1063, No. 1, 2005, pp. 1-8. doi:10.1016/j.brainres.2005.09.045

[10] G. D. Petrovich, "Learning and the Motivation to Eat: Forebrain Circuitry," Physiology \& Behavior, Vol. 104, No. 4, 2011, pp. 582-589. doi:10.1016/j.physbeh.2011.04.059

[11] J. Maniam and M. J. Morris, "The Link between Stress and Feeding Behaviour," Neuropharmacology, Vol. 63, No. 1, 2012, pp. 97-110. doi:10.1016/j.neuropharm.2012.04.017

[12] Z. Han, J. Q. Yan, G. G. Luo, Y. Liu and Y. Wang, "Leptin Receptor Expression in the Basolateral Nucleus of Conditioned Taste Aversion," World Journal of Gastroenterology, Vol. 9, No. 5, 2003, pp. 1034-1037.
[13] T. Huang, J. Yan and Y. Kang, "Role of the Central Amygdaloid Nucleus in Shaping the Discharge of Gustatory Neurons in the Rat Parabrachial Nucleus," Brain Research Bulletin, Vol. 61, No. 4, 2003, pp. 443-452. doi:10.1016/S0361-9230(03)00170-9

[14] C. B. Rosa, J. F. Goularte, N. A. Trindade, A. P. De Oliveira and A. A. Rasia-Filho, "Glutamate Microinjected in the Posterodorsal Medial Amygdala Induces Subtle Increase in the Consumption of a Three-Choice Macronutrient Self-Selection Diet in Male Rats," Anat Rec, Vol. 294, 2011, pp. 1226-1232. doi:10.1002/ar.21419

[15] B. M. King, K. N. Rossiter, S. G. Stines, G. M. Zaharan, J. T. Cook, M. D. Humphries and D. A. York, "Amygdaloid-Lesion Hyperphagia: Impaired Response to Caloric Challenges and Altered Macronutrient Selection," American Journal of Physiology: Regulatory, Integrative and Comparative Physiology, Vol. 275, No. 2, 1998, pp. R485R493.

[16] B. M. King, J. T. Cook, K. N. Rossiter and B. L. Rollins, "Obesity-Inducing Amygdala Lesions: Examination of Anterograde Degeneration and Retrograde Transport," American Journal of Physiology: Regulatory, Integrative and Comparative Physiology, Vol. 284, No. 4, 2003, pp. R965-R982.

[17] B. L. Rollins and B. M. King, "Amygdala-Lesion Obesity: What Is the Role of the Various Amygdaloid Nuclei?" merican Journal of Physiology: Regulatory, Integrative and Comparative Physiology, Vol. 279, No. 4, 2000, pp. R1348-R1356.

[18] J. S. de Olmos, C. A. Beltramino and G. Alheid, "Amygdala and Extended Amygdala of the Rat: A Cytoarchitectonical, Fibroarchitectonical, and Chemoarchitectonical Survey," In: G. Paxinos, Ed., The Rat Nervous System, Elsevier Academic Press, Amsterdam, 2004, pp. 509-603.

[19] A. Dall'Oglio, G. Gehlen, M. Achaval and A. A. RasiaFilho, "Dendritic Branching Features of Posterodorsal Medial Amygdala Neurons of Adult Male and Female Rats: Further Data Based on the Golgi Method," Neuroscience Letters, Vol. 430, No. 2, 2008, pp. 151-156. doi:10.1016/j.neulet.2007.10.051

[20] A. Dall'Oglio, G. Gehlen, M. Achaval and A. A. RasiaFilho, "Dendritic Branching Features of Golgi-Impregnated Neurons from the 'Ventral' Medial Amygdala Subnuclei of Adult Male and Female Rats," Neuroscience Letters, Vol. 439, No. 3, 2008, pp. 287-292. doi:10.1016/j.neulet.2008.05.025

[21] A. A. Rasia-Filho, F. Dalpian, I. C. Menezes, J. Brusco, J. E. Moreira and R. S. Cohen, "Dendritic Spines of the Medial Amygdala: Plasticity, Density, Shape, and Subcellular Modulation by Sex Steroids," Histology and Histopathology, Vol. 27, No. 8, 2012, pp. 985-1011.

[22] A. A. Rasia-Filho, D. Haas, A. P. De Oliveira, J. de Castilhos, R. Frey, D. Stein, V. M. Lazzari, F. Back, G. N. Pires, E. Pavesi, E. C. Winkelmann-Duarte and M. Giovenardi, "Morphological and Functional Features of the Sex Steroid-Responsive Posterodorsal Medial Amygdala of Adult Rats," Mini-Reviews in Medicinal Chemistry, Vol. 12, No. 11, 2012, pp. 1090-1106. doi: $10.2174 / 138955712802762211$ 
[23] A. M. Poulin, C. Lenglos, A. Mitra and E. Timofeeva, "Hypothalamic Expression of Urocortin 3 and the Type 2 Corticotropin-Releasing Factor Receptor Is Regulated According to Feeding State in Lean but Not Obese Zucker Rats," Neuropharmacology, Vol. 63, No. 1, 2012, pp. 147-153. doi:10.1016/j.neuropharm.2011.12.023

[24] E. Quagliotto, H. Neckel, D. F. Riveiro, K. R. Casali, C. Mostarda, M. C. Irigoyen, P. Dall'Ago and A. A. RasiaFilho, "Histamine in the Posterodorsal Medial Amygdala Modulates Cardiovascular Reflex Responses in Awake Rats," Neuroscience, Vol. 157, No. 4, 2008, pp. 709-719. doi:10.1016/j.neuroscience.2008.09.053

[25] H. Neckel, E. Quagliotto, K. R. Casali, N. Montano, P. Dal Lago and A. A. Rasia-Filho, "Glutamate and GABA in the Medial Amygdala Induce Selective Central Sympathetic/Parasympathetic Cardiovascular Responses," Canadian Journal of Physiology and Pharmacology, Vol. 90, No. 5, 2012, pp. 525-536. doi:10.1139/y2012-024

[26] S. W. Newman, "The Medial Extended Amygdala in Male Reproductive Behavior. A Node in the Mammalian Social Behavior Network," Annals of the New York Academy of Sciences, Vol. 877, 1999, pp. 242-257. doi:10.1111/j.1749-6632.1999.tb09271.x

[27] H. W. Dong, G. Petrovich and L. W. Swanson, "Topography of Projections from Amygdala to Bed Nuclei of the Stria Terminalis," Brain Research Reviews, Vol. 38, No. 1-2, 2001, pp. 192-246. doi:10.1016/S0165-0173(01)00079-0

[28] G. D. Petrovich, N. S. Canteras and L. W. Swanson, "Combinatorial Amygdalar Inputs to Hippocampal Domains and Hypothalamic Behavior Systems," Brain Research Reviews, Vol. 38, No. 1-2, 2001, pp. 247-289. doi:10.1016/S0165-0173(01)00080-7

[29] B.-H. Li, B. Xu, N. E. Rowland and S. P. Kalra, "c-fos Expression in the Rat Brain Following Central Administration of Neuropeptide Y and Effects of Food Consumption," Brain Research, Vol. 665, 1994, pp. 272-284. doi:10.1016/0006-8993(94)91348-X

[30] B. Xu, B.-H. Li, N. E. Rowland and S. P. Kalra, "Neuropeptide Y Injection into the Fourth Cerebroventricle Stimulates c-Fos Expression in the Paraventricular $\mathrm{Nu}-$ cleus and Other Nuclei in the Forebrain: Effect of Food Consumption," Brain Research, Vol. 698, No. 1-2, 1995, pp. 227-231. doi:10.1016/0006-8993(95)00905-6

[31] M. Decressac and R. A. Barker, "Neuropeptide Y and Its Role in CNS Disease and Repair," Experimental Neurology, Vol. 238, No. 2, 2012, pp. 265-272. doi:10.1016/j.expneurol.2012.09.004

[32] J. F. Flood and J. E. Morley, "Increased Food Intake by Neuropeptide Y Is Due to an Increased Motivation to Eat," Peptides, Vol. 12, No. 6, 1991, pp. 1329-1332. doi:10.1016/0196-9781(91)90215-B

[33] M. M. Durkin, M. W. Walker, K. E. Smith, E. L. Gustafson, C. Gerald and T. A. Branchek, "Expression of a Novel Neuropeptide Y Receptor Subtype Involved in Food Intake: An in Situ Hybridization Study of Y5 mRNA Distribution in Rat Brain," Experimental Neurology, Vol. 165, No. 1, 2000, pp. 90-100.

\section{doi:10.1006/exnr.2000.7446}

[34] S. D. Primeaux, D. A. York and G. A. Bray, "Neuropeptide Y Administration into the Amygdala Alters High Fat Food Intake," Peptides, Vol. 27, No. 7, 2006, pp. 16441651. doi:10.1016/j.peptides.2005.12.009

[35] W. Nicholas, R. Stewart and N. E. Badia-Elder, "Neuropeptide $\mathrm{Y}$ Administration into the Amygdala Suppresses Ethanol Drinking in Alcohol-Preferring Rats Following Multiple Deprivations," Pharmacology Biochemistry and Behavior, Vol. 90, No. 3, 2008, pp. 470-474. doi:10.1016/j.pbb.2008.04.005

[36] E. L. Gustafson, J. P. Card and R. Y. Moore, "Neuropeptide Y Localization in the Rat Amygdaloid Complex," The Journal of Comparative Neurology, Vol. 251, No. 3, 1986, pp. 349-362. doi:10.1002/cne.902510306

[37] B. M. Chronwall, D. A. Di Maggio, V. J. Massari, V. M. Pickel, D. A. Ruggiero and T. L. O'Donohue, "The Anatomy of Neuropeptide-Y-Containing Neurons in Rat Brain,' Neuroscience, Vol. 15, No. 4, 1985, pp. 1159-1181. doi:10.1016/0306-4522(85)90260-X

[38] M. L. Wolak, M. R. De Joseph, A. D. Cator, A. S. Mokashi, M. S. Brownfield and J. H. Urban, "Comparative Distribution of Neuropeptide Y Y1 and Y5 Receptors in the Rat Brain by Using Immunohistochemistry," The Journal of Comparative Neurology, Vol. 464, No. 3, 2003, pp. 285-311. doi:10.1002/cne.10823

[39] E. L. Gustafson, K. E. Smith, M. M. Durkin, M. W. Walker, C. Gerald, R. Weinshank and T. A. Branchek, "Distribution of the Neuropeptide Y Y2 Receptor mRNA in Rat Central Nervous System," Molecular Brain Research, Vol. 46, No. 1-2, 1997, pp. 223-235. doi:10.1016/S0169-328X(97)00017-X

[40] H. Higuchi, "Molecular Analysis of Central Feeding Regulation by Neuropeptide Y (NPY) Neurons with NPY Receptor Small Interfering RNAs (siRNAs)," Neurochemistry International, Vol. 61, No. 6, 2012, pp. 936941. doi:10.1016/j.neuint.2012.02.029

[41] G. Paxinos and C. Watson, "The Rat Brain in Stereotaxic Coordinates," Academic Press, San Diego, 2005.

[42] N. Hájos, T. J. Ellender, R. Zemankovics, E. O. Mann, R. Exley, S. J. Cragg, T. F. Freund and O. Paulsen, "Maintaining Network Activity in Submerged Hippocampal Slices: Importance of Oxygen Supply," European Journal of Neuroscience, Vol. 29, No. 2, 2009, pp. 319-327. doi:10.1111/j.1460-9568.2008.06577.x

[43] B. G. Stanley, D. R. Daniel, A. S. Chin and S. F. Leibowitz, "Paraventricular Nucleus Injection of Peptide YY and Neuropeptide Y Preferentially Enhance Carbohydrate Ingestion,” Peptides, Vol. 6, No. 6, 1985, pp. 1205-1211. doi:10.1016/0196-9781(85)90452-8

[44] A. F. Cezario, E. R. Ribeiro-Barbosa, M. V. Baldo and N. S. Canteras, "Hypothalamic Sites Responding to Predator Threats-The Role of the Dorsal Premammillary Nucleus in Unconditioned and Conditioned Antipredatory Defensive Behavior," European Journal of Neuroscience, Vol. 28, No. 5, 2008, pp. 1003-1015.

[45] S. Kollack-Walker and S. W. Newman, "Mating and Agonistic Behavior Produce Different Patterns of Fos 
Immunolabeling in the Male Syrian Hamster Brain," Neuroscience, Vol. 66, No. 3, 1995, pp. 721-736. doi:10.1016/0306-4522(94)00563-K

[46] L. A. Verhagen, M. C. Luijendijk, J. W. de Groot, L. P. van Dommelen, A. G. Klimstra, R. A. Adan and T. A. Roeling, "Anticipation of Meals during Restricted Feeding Increases Activity in the Hypothalamus in Rats," European Journal of Neuroscience, Vol. 34, No. 9, 2011, pp. 1485-1491. doi:10.1111/j.1460-9568.2011.07880.x

[47] S. Bi, Y. J. Kim and F. Zheng, "Dorsomedial Hypothalamic NPY and Energy Balance Control," Neuropeptides, Vol. 46, No. 6, 2012, pp. 309-314. doi:10.1016/j.npep.2012.09.002

[48] J. E. Morley, A. S. Levine, B. A. Gosnell, J. Kneip and M. Grace, "Effect of Neuropeptide Y on Ingestive Behaviors in the Rat," The American Journal of Physiology, Vol. 252, No. 3, 1987, pp. R599-R609.

[49] C. C. Welch, M. K. Grace, C. J. Billington and A. S. Levine, "Preference and Diet Type Affect Macronutrient Selection after Morphine, NPY, Norepinephrine, and Deprivation," The American Journal of Physiology, Vol. 266, No. 2, 1994, pp. R426-R433.

[50] E. Quagliotto, K. R. Casali, P. Dal Lago and A. A. Rasia-Filho, "Neurotransmitter and Neuropeptidergic Modulation of Cardiovascular Responses Evoked by the Posterodorsal Medial Amygdala of Adult Male Rats," In: D. Yilmazer-Hanke, Ed., Insights into the Amygdala, Nova Science Publishers, Hauppauge, 2012, pp. 139-165.

[51] A. A. Rasia-Filho, "Is There Anything 'Autonomous' in the Nervous System?" Advances in Physiology Education, Vol. 30, No. 1, 2006, pp. 9-12. doi:10.1152/advan.00022.2005

[52] G. L. Pereno, V. Balaszczuk and C. A. Beltramino, "Detection of Conspecific Pheromones Elicits Fos Expression in GABA and Calcium-Binding Cells of the Rat Vomeronasal System-Medial Extended Amygdala," Journal of Physiology and Biochemistry, Vol. 67, No. 1, 2011. pp. 71-85. doi:10.1007/s13105-010-0051-5

[53] C. B. Blake and M. Meredith, "Change in Number and
Activation of Androgen Receptor-Immunoreactive Cells in the Medial Amygdala in Response to Chemosensory Input," Neuroscience, Vol. 190, 2011, pp. 228-238. doi:10.1016/j.neuroscience.2011.05.056

[54] S. Marcuzzo, A. Dall'Oglio, M. F. Ribeiro, M. Achaval and A. A. Rasia-Filho, "Dendritic Spines in the Posterodorsal Medial Amygdala after Restraint Stress and Ageing in Rats," Neuroscience Letters, Vol. 424, No. 1, 2007, pp. 16-21. doi:10.1016/j.neulet.2007.07.019

[55] S. D. Primeaux, S. P. Wilson, M. C. Cusick, D. A. York and M. A. Wilson, "Effects of Altered Amygdalar Neuropeptide Y Expression on Anxiety-Related Behaviors," Neuropsychopharmacology, Vol. 30, 2005, pp. 15891597. doi:10.1038/sj.npp.1300705

[56] M. Heilig, S. McLoed, M. Brot, S. C. Heinrichs, F. Menzaghi, G. F. Koob and K. T. Britton, "AnxiolyticLike Actions of Neuropeptide Y: Mediation by Y1 Receptors in Amygdala, and Dissociation from Food Intake Effects," Neuropsychopharmacology, Vol. 8, 1993, pp. 357-363. doi:10.1038/npp.1993.35

[57] E. Knapska, K. Radwanska, T. Werka and L. Kaczmarek, "Functional Internal Complexity of Amygdala: Focus on Gene Activity Mapping after Behavioral Training and Drugs of Abuse," Physiological Review, Vol. 87, No. 4, 2007, pp. 1113-1173. doi:10.1152/physrev.00037.2006

[58] D. L. Drazen, M. D. Wortman, R. J. Seeley and S. C. Woods, "Neuropeptide Y Prepares Rats for Scheduled Feeding," American Journal of Physiology. Regulatory, Integrative and Comparative Physiology, Vol. 288, No. 6, 2005, pp. 1606-1611.

[59] A. P. Chambers and S. C. Woods, "The Role of Neuropeptide Y in Energy Homeostasis," Handbook of Experimental Pharmacology, Vol. 209, 2012, pp. 23-45. doi:10.1007/978-3-642-24716-3 2

[60] B. D. Sachs, "The Appetitive-Consummatory Distinction: Is This 100-Year-Old Baby Worth Saving? Reply to Ball and Balthazart," Hormones and Behavior, Vol. 53, No. 2, 2008, pp. 315-318. doi:10.1016/j.yhbeh.2007.11.015 